\title{
Flywheel/Heat Engine Power for an Energy-Economic Personal Vehicle
}

March 1976

Prepared for the Energy Research and Development Administration under Contract E(45-1):1830

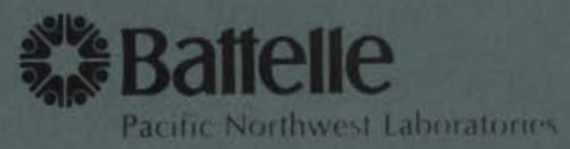


This report was prepared as an account of work sponsored by the United States Government. Neither the United States nor the Energy Research and Development Administration, nor any of their employees, nor any of their contractors, subcontractors, or their employees, makes any warranty, express or implied, or assumes any legal liability or responsibility for the accuracy, completeness or usefulness of any imformation, apparatus, product or process disclosed, or represents that its use would not infringe privately owned rights.

PACIFIC NORTHWEST LABORATORY

operated by

BATTELLE

for the

ENERCY RESEARCH AND DEVELOPMENT ADMINISTRATION

Under Contract E(45-1)-1830

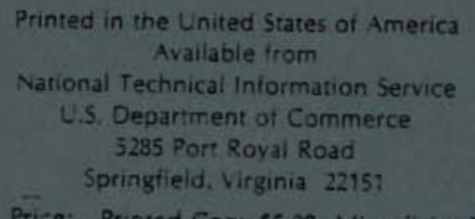

Price: Printed Copy \$5.00; Microfiche $\$ 2.25$ 


\section{FLYWHEEL/HEAT ENGINE POWER FOR AN ENERGY-ECONOMIC PERSONAL VEHICLE}

by V. Loscutoff

March 1976

Battelle

Pacific Northwest Laboratories

Richland, Washington 99352 


\section{SUMMARY}

New materials and energy problems are increasing the feasibility of using flywheel energy storage systems to power personal automobiles. A promising concept appears to be the combination of the high specific power density of a flywheel with the high specific energy density of a small heat engine. This report presents a technical and fuel economy assessment of a small personal vehicle powered by a hybrid flywheel/heat engine drive system.

Technical evaluations indicate that a flywheel/heat engine system based on improved materials technology could serve as a practical vehicle drive. While somewhat limited in performance, the proposed system could produce significant improvements in fuel consumption rates. Technological advancements in materials and power transmission systems would make flywheel/heat engine systems even more attractive. 


\section{CONTENTS}

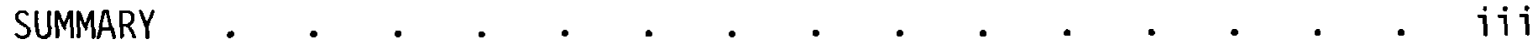

INTRODUCTION

STUDY OBJECTIVE $\quad$ •

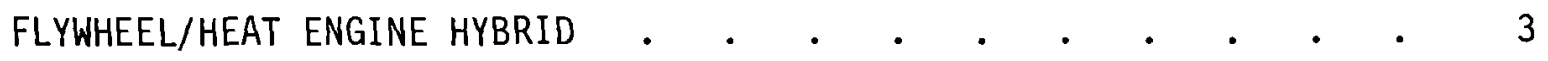

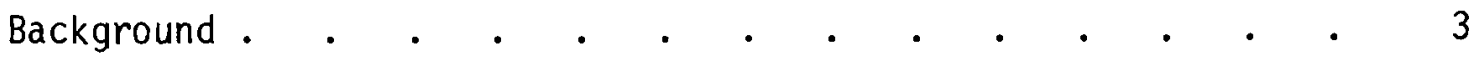

Flywheel System Properties . . . . . . . . . . . 4

Energy Conservation Potential • • . . . . . . . . 6

Flywhee1/Heat Engine Hybrid Design Performance . . . . $\quad 8$

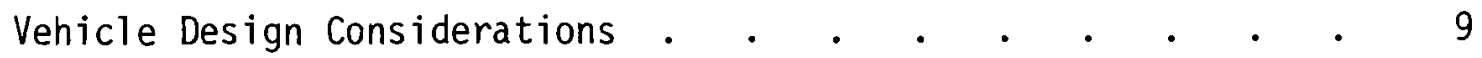

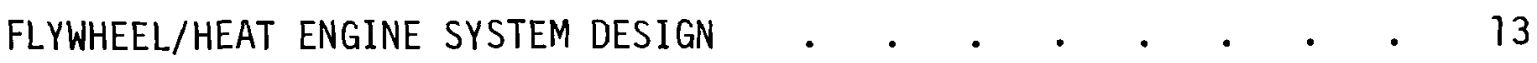

Flywhee1 and Heat Engine Selection . . . . . . . . 13

Flywheel Material, Bearings, and Seals . . . . . . . 14

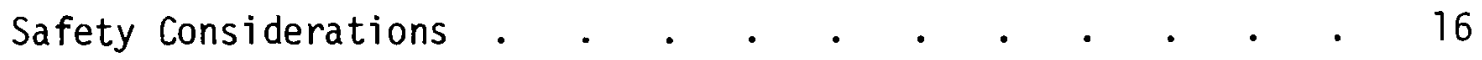

Flywhee1/Heat Engine System Configuration . • • • • • 17

FLYWHEEL/HEAT ENGINE AND CURRENT TRANSPORTATION SYSTEMS • • • • 21

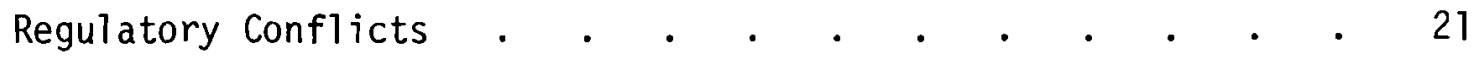

Maintenance and Operation . . . . . . . . . . . . . 21

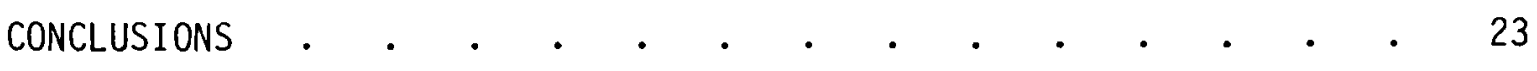

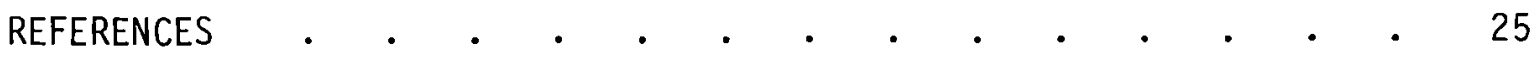

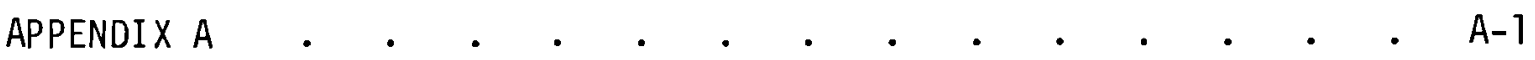


FLYWHEEL/HEAT ENGINE POWER

FOR AN ENERGY-ECONOMIC PERSONAL VEHICLE

\section{INTRODUCTION}

The automobile in the U.S. enjoys the distinction of being a source of convenient, safe, rapid and personalized transportation. Americans tend to judge and select their automobiles on the basis of specific characteristics and performance capabilities, which sometimes far exceed actual needs. This leads to inefficient use of the automobile, resulting in waste of natural resources.

Today, new factors entering the transportation sector are forcing changes in attitudes toward the automobile. The magnitude of the automobile industry, which is significantly dependent upon natural resources, is threatened by possible limitations in these resources. The most immediate threat is posed by limits to availability of the energy source to power automobiles--petroleum. The high cost of imported crude oil and an apparent marginal ability of the United States to produce a 11 the required petroleum have encouraged a recent trend toward gradually scaling down current vehicles to improve fuel economy.

The extent of petroleum dependence by future personal vehicles must be minimized. The industry's ultimate response will be, by necessity, a total redesign of the power system and superstructure of the automobile.

Alternative vehicles, such as electric cars, provide a potential solution to the problem. However, electric cars have their own inherent drawbacks. An alternate approach could be to utilize fuel more economically by increasing the gas mileage to 80 to 100 miles per gallon for each vehicle. This alternative is to incorporate high energy density heat engines with high power density flywheels. Such a design would provide an optimal vehicle drive system which synergistically combines the most desirable characteristics of the two energy systems. This study examines the concept and its potential for reducing automobile gasoline consumption by a factor of three or more. 


\section{STUDY OBJECTIVE}

The primary objective of this study is to examine the flywheel/heat engine hybrid as a potential energy-economic drive for personal vehicles, using technical, economic, and performance criteria. The vehicle described here is a concept with all elements keyed to the propulsion system. This concept includes the following fundamentals of automobile engineering:

- engines designed to operate at peak efficiency at a11 times,

- aerodynamically designed carriages,

- body and chassis designed for minimum weight,

- tires with high pressures and narrow tread,

- reduction in accessories.

The key to the proposed vehicle is a drive system possessing the economy of a small internal combustion engine (about $10 \mathrm{hp}$ ) and the performance of a 100-hp internal combustion engine when measured by acceleration, hill climbing and peak speeds.

The most significant characteristic of the proposed flywheel/heat engine propulsion system is a very small fuel engine in series with a very large flywheel. The interfaces between engine and flywheel, and between flywheel and wheels, are infinitely variable traction transmissions. All other features of the vehicle are similar to those of current vehicles, except for the design modifications, which are according to the fundamentals listed above. 


\section{FLYWHEEL/HEAT ENGINE HYBRID}

\section{BACKGROUND}

The first major vehicular application of flywheels was the 0erlikon Electrogyro bus, used in European and African transit services in the 1950s. The buses were technically successful and economically feasible. However, long waits between recharges and difficulties imposed on the vehicle operators forced a gradual withdrawal of these buses from service.

Lockheed has worked on a program to demonstrate flywheel propulsion systems in San Francisco using a dual mode vehicle operating either from energy supplied by the flywheel or from energy supplied by trolley wires. Initial analysis suggested an effective electric vehicle with increased route flexibility. Lockheed has also examined several flywheel and flywheel hybrid concepts in detail for the Environmental Protection Agency. $(2,3,4)$ Their studies centered on the hybrid of a small flywheel with a slightly reduced engine, about 50 percent of normal power plant. This system was found to offer only minor advantages over the conventional automobile drive system in terms of economy and emissions. Furthermore, the high performance was limited to a small number of cycles because the small flywheel was discharged after only brief use. Incidentally, the study also found that a pure flywheel drive system was impractical for a conventional American automobile. The biggest drawback was the size of the drive system necessary to give a 5000-1b vehicle a 200-mile range. However, special purpose vehicles with a limited range were found to be excellent candidates for flywheel power systems.

In addition, Garrett Research is currently testing flywheels as a means for regenerative braking in the New York subway system. (5) Large flywheels absorb braking energy during stops and give it up upon demand during accelerations or emergencies. The Garrett tests indicate the regenerative system could reduce electrical energy demands by nearly 10 percent and, in addition, provide sufficient power for the trains to reach the next station in the event of a power failure. 
In addition to the flywheel power units just described, other variations of flywheel-driven vehicles are feasible as transportation alternatives. The system proposed in this report--a large flywheel in series with a small internal combustion engine (ICE)--is one variation which had not undergone prior extensive analysis.

This study considers a particular flywheel/ICE hybrid which is dominated by the flywheel. In terms of performance (acceleration, top speed, hillclimbing ability) and energy economy, the proposed system appears to be a satisfactory substitute for currently manufactured automobiles.

The characteristics of the proposed hybrid system match those required of a personal vehicle quite well. A flywheel can provide high power density levels to propel vehicles at desired velocities and accelerations. With a bilateral transmission, a flywheel system can store vehicle kinetic energy during braking for use during acceleration, thereby increasing the energy efficiency of the vehicle. In addition, flywheels have an almost unlimited cycle life, compatible with service-life requirements of the complete vehicle drive system. A small heat engine has very high energy density levels but very low power density levels. Thus, a flywheel/heat engine hybrid combines the best features of each to provide an excellent vehicle drive system.

\section{FLYWHEEL SYSTEM PROPERTIES}

The attractiveness of flywheel systems in transport vehicles lies in the inherent characteristics of the flywheel. The amount of energy stored in a flywhee 1 is a function of the mass and angular velocity of the flywheel. The amount of power which can be taken from, or put into, a flywheel depends on the flywheel and the interface with wheels, normally a transmission. Furthermore, a flywheel can be charged and discharged a large number of times without concern about degree of discharge. These advantages are compared to those of battery storage systems in Table 1.

These comparisons suggest that a flywheel energy storage system matches or exceeds conventional battery systems in terms of energy density, power density and 1 ife. The flywheel system falls short of the energy density 
TABLE 1. Flywhee 1-Battery Comparison (1)

Energy System

Lead-acid battery

Nickel-cadmium battery

Maraging steel flywheel

4340 steel flywhee 1

PRD-49 fiberglass flywheel

Fused silica flywheel

Heat engine
Energy
Density
W-hr/lb

10

14

28

15

60

200

1000
Power

Density

$w / 1 b$

80

80

$>10^{4}$

$>10^{4}$

$>10^{4}$

$>10^{4}$

1000
Discharge

Cycle (75\%)

Life, Cycles

$$
300-500
$$

$1000-3000$

$>10^{5}$

$>10^{5}$

$>10^{5}$

$>10^{5}$

$>10^{5}$

capabilities of an internal combustion engine. However, when combined with a small internal combustion engine, the flywheel yields an ideal high performance and energy-economic vehicle drive system.

Development of an inexpensive, efficient, lightweight storage battery for electric vehicles would allow efficient transportation use of electric energy generated by nuclear power plants. However, such vehicles would be limited by a range of about 100 miles for 4000 1b of lead-acid batteries and $400 \mathrm{lb}$ of sodium-sulfur batteries, because recharging is slow due to power, heat and battery life limitations. (6) Further, battery replacements to extend vehicle range, while possible, are considerably more complicated than the replacement of liquid fuels. In a future all-electric-energy society, improved batteries would be the primary vehicle energy system. In the interim, flywheel/heat engine drive could provide a more feasible alternative.

The amount of energy stored in a flywheel could, in principle, be increased indefinitely by a continuous increase in angular velocity. However, the ultimate limit of energy stored in a flywheel is set by the tensile strength of the flywheel material. For simple configurations, it can be easily shown that the maximum amount of energy stored per unit weight of the flywheel material is equal to

$$
E_{\max }=K_{s} \frac{\sigma}{\rho}
$$


where

$$
\begin{aligned}
E_{\max } & =\text { maximum specific energy, 1b-in./1b } \\
K_{S} & =\text { shape factor, dimensionless } \\
\sigma & =\text { ultimate tensile strength, } 1 \mathrm{~b} / \mathrm{in}^{2} \\
\rho & =\text { density, } 1 \mathrm{~b} / \mathrm{in}^{3}
\end{aligned}
$$

Incorporation of new materials into the design of flywheels can yield energy storage systems highly suitable for current mini-automobiles. For example, the flywheel used in the 0erlikon bus had a maximum energy density level of $2.7 \mathrm{~W}$-hr/1b. (7) Recent tests of maraging steel flywheels have been conducted at an energy density level of $25 \mathrm{~W}-\mathrm{hr} / 1 \mathrm{~b}$, nearly 10 times that of the 0erlikon bus system. $(7,8)$ Further applications of new materials promise close to a tenfold increase in energy densities for flywheels. This would make them nearly competitive with smaller internal combustion engines in terms of energy density.

\section{ENERGY CONSERVATION POTENTIAL}

Current internal combustion engines are seldom operated at maximum power, the state at which maximum thermal efficiency is achieved. One study has estimated that the American automobile uses maximum power only 1 percent of the time; less than 10 percent of engine power is used 43 percent of the time. (9) As a result, efficiency of present engines is very low.

The loss in efficiency at part throttle has three sources:

- the mechanical friction of large engines run at moderate speeds;

- the energy required to purnp all intake air past a partially closed throttle plate into the low pressure intake manifold;

- the larger fraction of heat of combustion rejected to the cylinder walls.

The degradation of thermal efficiency due to these factors exceeds 50 percent at part load. 
Idling is the most inefficient of all operating modes because it wastes fuel while doing no useful work. Considerable potential for fuel savings exists in utilizing the idling periods effectively by storing the energy generated during idling.

Table 2 summarizes Kummer's calculations of thermal efficiency degradation at typical part load. (10) The calculations are based on a 1971 Ford Pinto, $2000 \mathrm{cc}, 4-c y l i n d e r$ engine with an automatic transmission. Note that the thermal efficiency at wheels is only 8.5 percent; hence, the fue 1 economy can be improved significantly with more effective engine utilization. An estimate of actual improvement in the exemplary Pinto is up to $38 \mathrm{mpg}$ in city driving. One existing project seeks to demonstrate this with a small flywheel (150 1b for the entire flywheel package).

TABLE 2. Degradation of Thermal Efficiency in an Automobile (10)

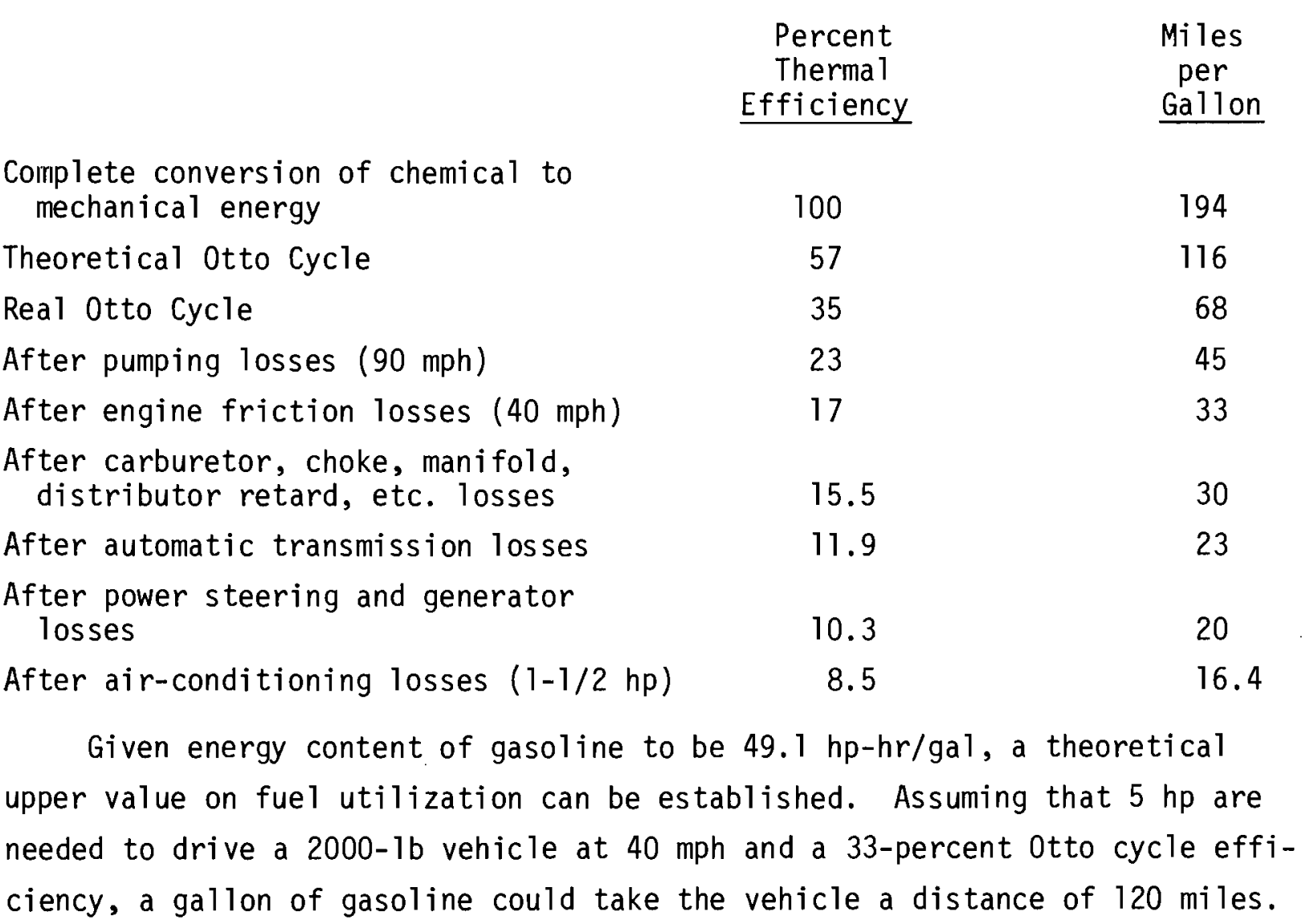


While this is high, it is not unreasonable and could be attained with good design and driving practice. In view of these numbers, $60 \mathrm{mpg}$ is not unreasonable for a lightweight car. In fact, one current study expects to demonstrate $51 \mathrm{mpg}$ for a Honda Civic in city driving by using a small flywheel for energy storage.

The foregoing results suggest that the potential is high for internal combustion engines designed for minimum fuel consumption. This potential may be realized by combining a large flywheel with a heat engine.

\section{FLYWHEEL/HEAT ENGINE HYBRID DESIGN PERFORMANCE}

The proposed system is based on a cycle several hours long, plus an added factor for emergencies. This differs from the system analyzed by Lockheed, (3) which was based on the maintenance of constant total kinetic energy of the vehicle. Implicit in the Lockheed system was the control of heat engine output to hold the sum of the kinetic energies of the flywheel and the vehicle at a constant value. In the proposed system, heat engine output is held at a nearly constant optimum level; its sole function is to charge the flywheel. The flywheel is the only source of power to the wheels and is maintained at operational power levels by the internal combustion engine. Thus, vehicle performance is dependent upon flywheel power, not heat engine rated power.

The choice of flywheel size is largely a question of assessing tradeoffs between performance and cost or between one figure of merit and another. Optimization of a hybrid vehicle design requires some criterion, such as statistical frequency and magnitudes of demands imposed on the vehicle, for determining intermediate reserve storage capacity. Since this study is limited to a fuel economy appraisal, the hybrid system was arbitrarily selected to consist of a 10.0-kWh flywheel in series with a $7.5-\mathrm{kW}$ (10 hp) heat engine.

The performance of the candidate vehicle, in terms of top speed and acceleration, would equal that of current small-sized automobiles. For discussion purposes, a peak possible speed could be 100 mph; the acceleration 
would be such that speed could increase from 0 to $60 \mathrm{mph}$ in about $15 \mathrm{sec}$. However, this would be obtained at a sacrifice in vehicle range. The cruising speed would be about $50 \mathrm{mph}$. Lower cruising speeds are necessary to maximize vehicle range, which would depend on the capacity of the gasoline tarik. With a 5-gal tank, the range could be 500 miles. It would be lower at higher speeds and when high headwinds are encountered. The specified performance variables can be easily increased by increasing the heat engine power rating by a few kilowatts. The optimum combination of a flywheel and a heat engine would be determined by the auxiliary system needs and the overall efficiency of the drive train system. A summary of possible hybrid vehicle specifications and performance is given in Table 3. Road performance and economy characteristics are calculated for a number of representative conditions in Appendix A.

TABLE 3. Performance of Flywheel/Heat Engine Hybrid

$\begin{array}{lll}\text { Heat engine } & - & 7.5 \mathrm{~kW} \\ \text { Flywheel energy capacity } & - & 10 \mathrm{kWh} \\ \text { Depth of flywheel discharge } & - & 75 \% \\ \text { Maximum speed } & -100 \mathrm{mph} \\ \text { Cruising speed } & -50 \mathrm{mph} \\ \text { Range (at cruising speed) } & -200 \mathrm{miles} \\ \text { Velocity on } 20 \% \text { grade } & -50 \mathrm{mph}\end{array}$

The flywheel in a hybrid vehicle could provide approximately $36,000 \mathrm{hp}$ sec, which may be distributed in any desirable mode. For example, the flywheel could provide $60 \mathrm{hp}$ for $10 \mathrm{~min}$, or $600 \mathrm{hp}$ for $1 \mathrm{~min}$, before becoming discharged. However, this is not "running out of gas;" the 7.5-kW heat engine would then be used to reach destination, but at a slower speed.

\section{VEHICLE DESIGN CONSIDERATIONS}

The personal vehicle proposed in this study is a concept with all elements keyed to minimizing energy consumption. This includes most of the fundamental aspects of automobile engineering. While safety is very 
important and is a prime factor in the hybrid vehicle design, comfort has to be secondary to energy savings. An energy economic design must be dedicated to reducing friction, drag and weight. Such luxuries as air conditioning, power seats and power windows are out of the question in vehicles designed for economy.

At moderate and high speeds, the major loss in a vehicle is aerodynamic drag. It accounts for nearly one-half the power lost in average vehicle operation. Power lost to drag is expressed by

$$
H P_{D}=\frac{C_{D} A V^{3}}{146,625}=h p
$$

where

$$
\begin{aligned}
& C_{D}=\text { drag coefficient } \\
& A=\text { frontal area, } \mathrm{ft}^{2} \\
& V=\text { velocity, miles } / \mathrm{hr}
\end{aligned}
$$

Little can be done about velocity since an upper limit of at least 50 mph is necessary. The frontal area can be minimized to some extent by using semireclining and very low seating positions for passengers. Proper aerodynamic design can reduce drag coefficients from the present range of 0.45 to 0.55 down to the range of 0.2 to 0.3 with advanced design techniques. With a reasonable drag coefficient of 0.4 , a frontal area of $16 \mathrm{ft}^{2}$ and a velocity of $50 \mathrm{mph}$, the drag loss is

$$
H P_{D}=\frac{(0.4)(18)(50)^{3}}{146,625}=6.4 \mathrm{hp}(4.58 \mathrm{~kW})
$$

It is obvious that proper design can bring the losses down by significant factors. A decrease in speed to $30 \mathrm{mph}$ for city driving would decrease drag losses to about $1 \mathrm{hp}$. However, there would be additional losses due to acceleration, grades, and friction. 
Another major contributor to vehicle losses is the road load component made up of tire loss, bearing loss, and power train loss. The dominant factor, tire loss, accounts for nearly 85 percent of the total. Advanced tire designs with special rubber compounding, reduced width, stiffer sidewalls and reduced aspect ratios, can reduce rolling resistance by almost 60 percent. At $50 \mathrm{mph}$, the rolling resistance loss could be kept under $2 \mathrm{hp}(1.5 \mathrm{~kW})$. There may be a loss in stability and a harsher ride due to these tire modifications. For a commuter vehicle, these should not be excessively objectionable.

Bearing and power train losses can be significantly reduced by avoiding packed wheel bearings, using magnetic seals to cut drag, and using drysump transmissions. Variable speed transmissions can substantially improve energy throughput efficiencies. The resulting losses should be less than $1 \mathrm{hp}$ at $50 \mathrm{mph}$.

A third major contributor to vehicle road losses is associated with vehicle acceleration and braking. These losses are magnified by stop-andgo driving which is common to an urban vehicle. The acceleration losses are given by

$$
H P_{A}=\frac{m a V}{375}+\sum_{i=1}^{n} \frac{I_{i} \alpha_{i} \omega_{i}}{550}
$$

where

$$
\begin{aligned}
& \mathrm{m}=\text { vehicle mass, slugs } \\
& \mathrm{a}=\text { linear acceleration, } \mathrm{ft} / \mathrm{sec}^{2} \\
& \mathrm{~V}=\text { linear velocity, miles } / \mathrm{hr} \\
& \mathrm{I}=\text { moment of inertia, slug- } \mathrm{ft}^{2} \\
& \alpha=\text { angular acceleration, } \mathrm{rad} / \mathrm{sec}^{2} \\
& \omega=\text { angular velocity, } \mathrm{rad} / \mathrm{sec}
\end{aligned}
$$

Acceleration losses can be minimized by diminishing the vehicle weight and number of accelerations. 
Acceleration losses can also be reduced by transforming the kinetic energy of the vehicle into kinetic energy of the flywheel through regenerative braking. In urban situations, this could mean a 10 percent or greater reduction in energy consumption.

Summing up all the power demands at $50 \mathrm{mph}$, the power which must be produced by the vehicle motor system is about $10 \mathrm{hp}$ or about $7.5 \mathrm{~kW}$. The additional power is required for lights and other auxiliary systems. Very heavy loads, such as air conditioners and heavy duty heaters, have been ignored and will require their own power sources when incorporated into the proposed vehicle. 


\section{FLYWHEEL/HEAT ENGINE SYSTEM DESIGN}

\section{FLYWHEEL AND HEAT ENGINE SELECTION}

The drive system of the proposed vehicle is a $7.5-\mathrm{kW}$ internal combustion engine in series with a 10-kWh flywhee1. Operation and performance of this drive system is based upon approximately four hours of continuous operation at $50 \mathrm{mph}$, during which the average losses to wind drag, rolling drag, and other factors are about $10.0 \mathrm{~kW}$. During the four-hour period, the heat engine provides $30.0 \mathrm{kWh}$ and the flywheel provides $10 \mathrm{kWh}$ of energy. After the four-hour period, the flywhee 1 will be depleted of nearly al1 energy and the heat engine will be the source of al1 motive power. If an 8.5-kW heat engine is used over the same cycle instead, the flywheel will be nearly one-half charged at the end of the four-hour period. For city driving under $30 \mathrm{mph}$, the flywheel alone can power the vehicle for about 100 miles.

The choice of a heat engine is determined by the need of the engine to charge the flywheel whenever it is below the peak level and the driving cycle. Such an engine would be designed to operate at optimum efficiency at a single operating point. Since heat engine technology is we11established, additional investigations in this area are not pursued in this study.

In normal operation, the engine charges the flywheel continuously, during both transit and stops. If the flywheel is completely discharged, the $7.5-\mathrm{kW}$ engine can provide sufficient power to drive the vehicle at about $45 \mathrm{mph}$, although acceleration and hill-climbing ability will be severely impaired. The system can be designed to shut off the engine automatically when the flywheel is fully charged, and to restart it automatically when the flywheel charge level falls below a specified value. 
FLYWHEEL MATERIAL, BEARINGS, AND SEALS

The flywheel for the proposed drive system is limited in size by a number of considerations, the most important of which are material and physical dimensions. For the purposes of this study, the flywheel material is modified steel. The maximum diameter of the flywheel is limited to $30 \mathrm{in}$. to allow for the containment ring and the vacuum housing. With these limitations, a possible candidate flywheel could be designed with a rating of $10 \mathrm{kWh}$. The significant characteristics for a 10-kWh flywheel made of modified AISI 4340 grade steel with an ultimate stress of $260 \mathrm{ksi}$ are as follows:

- Configuration - modified exponential

- Energy level - $10 \mathrm{kWh}$

- Energy density - $14.3 \mathrm{~W}-\mathrm{hr} / \mathrm{lb}$

- Weight - $700 \mathrm{1b}$

- Diameter - 30 in.

- Speed - 24,000 rpm

- Maximum working stress - $160 \mathrm{ksi}$

- Shape factor - 0.88

The design procedure for the sample flywheel is presented in Appendix A.

Other materials with potentially better energy, weight, and stress characteristics can be used. Table 4 lists 12 available candidate materials. The most important factor omitted from the table is the cost of each material. However, it is felt that current costs would not reflect the true costs of a system if large-scale production is assumed.

The bearings for a flywheel system do not present a very significant obstacle to flywheel system development. Conventional bearings and lubricants appear to be adequate for most vehicle drive systems, since the loads are relatively low and loss requirements are modest. Furthermore, ball bearing systems are highly refined and reliable; bearing lives exceed the $10,000 \mathrm{hr}$ necessary for public transportation. 
TABLE 4. Flywheel Material

\begin{tabular}{|c|c|c|c|c|}
\hline Material & $\begin{array}{l}\text { Ultimate } \\
\text { Tensile } \\
\text { Stress, } \\
\mathrm{kg} / \mathrm{cm}^{2} \times 10^{3} \\
\end{array}$ & $\begin{array}{c}\text { Working } \\
\text { Stress } \\
\mathrm{kg} / \mathrm{cm}^{2} \times 103 \\
\end{array}$ & $\begin{array}{l}\text { Density } \\
\mathrm{kg} / \mathrm{cm}^{3} \\
\times 10^{-3} \\
\end{array}$ & $\begin{array}{l}\mathrm{kg}-\mathrm{cm} / \mathrm{kg} \\
\times 106 \\
(\mathrm{~W}-\mathrm{hr} / 1 \mathrm{~b}) \\
\end{array}$ \\
\hline "E" Glass/polyester & 11.60 & 4.71 & 1.9 & $\begin{array}{c}2.41 \\
(29.75)\end{array}$ \\
\hline "R" G1ass/polyester & 13.71 & 4.71 & 1.8 & $\begin{array}{c}2.61 \\
(32.22)\end{array}$ \\
\hline S-1014 Glass & 17.57 & 6.12 & 1.8 & $\begin{array}{c}3.40 \\
(41.97)\end{array}$ \\
\hline Kevlar 49 & 33.76 & 16.87 & 1.4 & $\begin{array}{c}12.05 \\
(148.76)\end{array}$ \\
\hline 2024-T851 Aluminum & 4.57 & 2.46 & 2.8 & $\begin{array}{c}0.88 \\
(10.86)\end{array}$ \\
\hline $18 \mathrm{Ni}-400$ Stee 1 & 28.75 & 18.28 & 7.8 & $\begin{array}{c}2.34 \\
(28.89)\end{array}$ \\
\hline 4340 Stee 1 & 18.28 & 11.26 & 7.8 & $\begin{array}{c}1.44 \\
(17.77)\end{array}$ \\
\hline Graphi te & 16.80 & 8.40 & 1.4 & $\begin{array}{c}6.00 \\
(74.07)\end{array}$ \\
\hline Boron & 29.80 & 14.90 & 2.6 & $\begin{array}{c}5.73 \\
(70.74)\end{array}$ \\
\hline Wood (redwood) & 1.12 & 0.56 & 0.40 & $\begin{array}{c}1.40 \\
(17.28)\end{array}$ \\
\hline Bamboo & 3.66 & 1.83 & 0.56 & $\begin{array}{c}3.27 \\
(40.37)\end{array}$ \\
\hline Titanium & 9.15 & 4.60 & 4.6 & $\begin{array}{c}1.00 \\
(12.35)\end{array}$ \\
\hline \multicolumn{5}{|c|}{$\begin{array}{l}\text { Advanced bearings (e.g., fluid and magnetic) may eventually replace } \\
\text { bearings as flywheel material technology improves and speeds rise } \\
\text { antially. Fluid-film bearings can use oil, grease, or gas as the } \\
\text { dynamic support medium. Because of the additional fluid pressures } \\
\text { ved with these bearings, rubbing seals or magnetic fluid seals are }\end{array}$} \\
\hline
\end{tabular}


Magnetic bearings offer the greatest potential for very low friction and drag losses. However, a failure of the magnetic levitation device will lead to a collapse of the bearing and possible destruction of the flywhee 1 system. For this reason, magnetic bearings will probably always be designed with a ball bearing system as a back-up in flywheel systems.

A large potential loss in flywheel systems is associated with seals in a mechanical power feedthrough. Current seals can be used for transport vehicles in spite of large friction losses. Labyrinth seals are characterized by low losses and long life. Ferrofluidic seals show great promise but have not demonstrated the long life necessary for vehicle operation. Two alternatives to seals are possible: magnetic couplings and locating the motor generator in a vacuum.

The bearing and seal friction losses for a 10-kWh flywheel energy storage system should not exceed $1 \mathrm{~kW}$ if the system is used to propel a vehicle. Estimates of performance of these systems indicate that losses can be kept at this level but would require some improvement of current components. (4) It will also be necessary to accumulate significant experimental information to verify the loss and lifetime performances.

\section{SAFETY CONSIDERATIONS}

The proposed $f 1 y$ wheel/heat engine system requires analysis and testing to determine the extent of possible dangers inherent in the application of a flywheel. Two known problems must be solved.

First, a 700-1b flywhee 1 rated at $10 \mathrm{kWh}$ contains the same potential energy as $2 \mathrm{lb}$ of gasoline or $20 \mathrm{lb}$ of TNT. A sudden change in the state of the flywheel could produce a dangerous situation. In case of an accidental occurrence, the flywheel energy must be dissipated slowly. One possible solution would be to combine programmed flywheel disintegration with a high factor of safety and extensive quality control of the final product.

Al though a somewhat lesser danger, gyroscopic effects represent an area of concern to vehicle control. The gyroscopic effects on a vehicle dominated 
by a flywheel dictate a gimbal-mounted flywheel, permitting large lateral motions. The following sample calculation demonstrates the significant potential gyroscopic precession force relative to the size of the vehicle.

Assume a maximum vehicle pitch rate of $\omega_{1}=0.1 \mathrm{rad} / \mathrm{sec}$ and a bearing spacing of $L=18 \mathrm{in}$. The gyroscopic precession force $F$ acting on each bearing at $24,000 \mathrm{rpm}\left(\omega_{2}=2512 \mathrm{rad} / \mathrm{sec}\right)$ would be

$$
F=\frac{I_{0} \omega_{1} \omega_{2}}{L}=\frac{(101)(2512)(0.1)}{18}=14101 \mathrm{bs}
$$

where I is the moment of inertia for the flywheel rotor.

Forces of this magnitude must be minimized. One possible means is to use a pair of counterrotating flywheels on the same shaft to eliminate the external gyroscopic torques. However, this generates additional torques on flywheel shafts and bearings. Gimbaling the flywheel system with allowable motion of $\pm 10^{\circ}$ should minimize the undesirable torques. As a safety measure, the flywheel unit could be designed to separate from the vehicle main structure in cases of excess angular displacements such as those which may result from accidents. An alternative would be to reduce the size of the flywheel, which may mean reducing flywheel energy to $1.0 \mathrm{kWh}$ maximum.

\section{FLYWHEEL/HEAT ENGINE SYSTEM CONFIGURATION}

The proposed vehicle drive system is shown schematically in Figure 1. A 7.5-kW internal combustion engine, designed to operate at about $5000 \mathrm{rpm}$ at the designed torque-speed rating, charges the flywheel at a steady $7.0 \mathrm{~kW}$ if some losses are included. Power is supplied to the flywheel through a continuously variable transmission, which adjusts automatically to maintain the engine at design speed while the flywheel varies between 12,000 and $24,000 \mathrm{rpm}$. Another continuously variable transmission with 


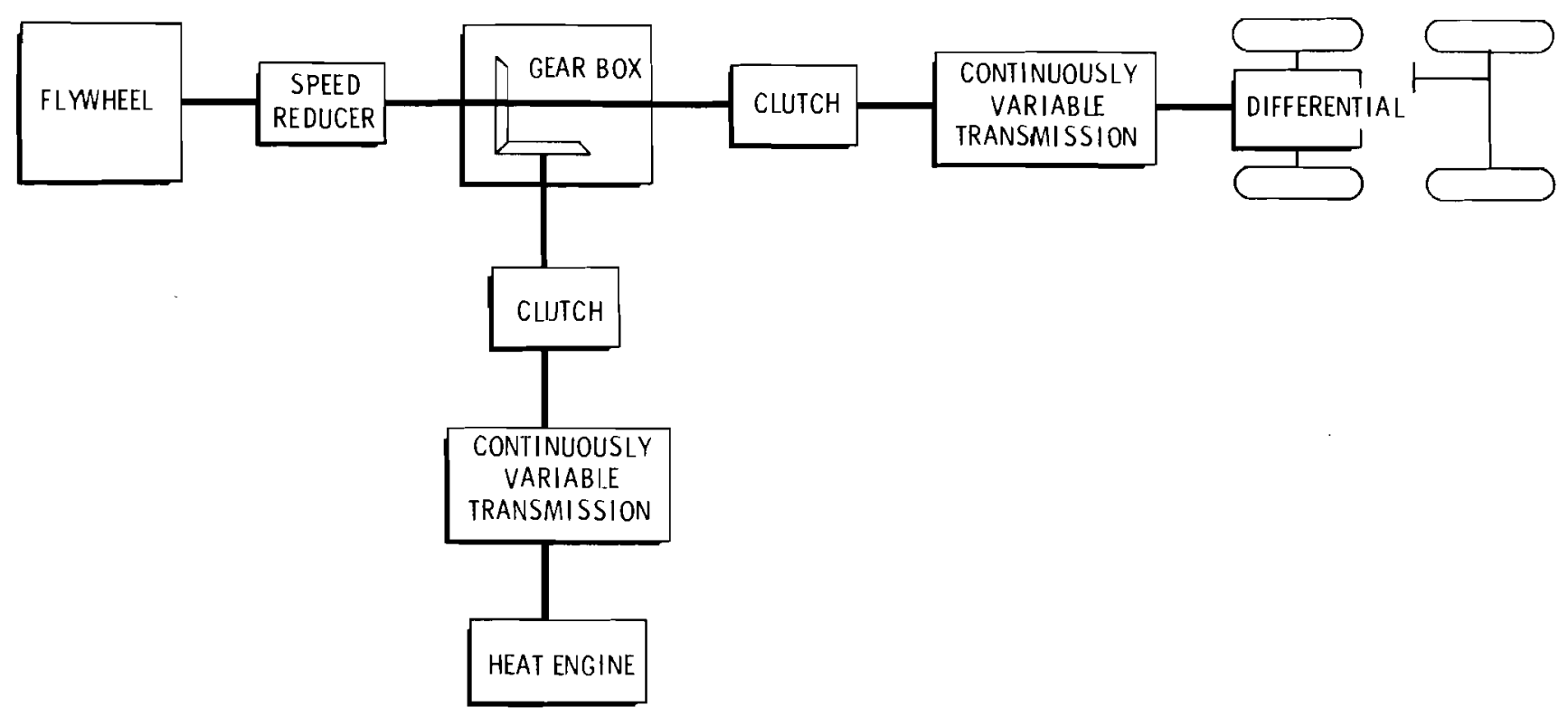

FIGURE 1. Flywheel/Heat Engine Vehicle Schematic

reversing capabilities drives the wheels using the flywheel energy. There is no need at any time to vary the speed of the engine to compensate for changes in demand, except when the flywheel is fully charged. At this time, the engine is turned off automatically, to be turned on automatically when the energy level in the flywheel falls below a specified level.

It is possible to operate the engine without a transmission to the flywheel. If the flywheel is assumed to discharge at one-fourth of its maximum rated energy level, the charge/discharge speed ratio is $2: 1$. Thus, the engine speed ratio is $2: 1$ (5000 rpm to $2500 \mathrm{rpm}$ ). The engine will operate in a range slightly off the optimal, which will result in a higher fuel consumption rate. Overall system efficiency is higher than could be obtained with fixed point engine operation, however, because of losses associated with a transmission. The engine would be coupled to the flywheel by an efficient speed reduction unit and a simple clutch. There may be start-up difficulties with a completely stopped flywheel as well as operating problems with a nearly discharged flywheel. 
The flywheel is contained in a vacuum system to minimize the windage losses. With pressures near $10^{-2}$ torr, the flywheel could run nearly a week before discharging sufficiently to excite the internal combustion engine.

The traction transmissions can be used to provide regenerative braking. This could yield large savings in energy during stop-go urban driving. Traction transmissions are 87 to 95 percent efficient in the forward direction and somewhat lower in reverse. 


\section{FLYWHEEL/HEAT ENGINE AND CURRENT TRANSPORTATION SYSTEMS}

\section{REGULATORY CONFLICTS}

Government required safety features, such as 5 -mph bumpers and side guard beams, add proportionately more weight to a light vehicle than to a heavier automobile. Achievement of the 100-mpg flywheel/heat engine vehicle will necessitate obtaining exemptions from certain regulations. A precedent for doing so has al ready been set. Sebring Vanguard, manufacturer of the small electric "Citi-Car," has obtained exemptions from some safety regulations for its vehicle. Thus, while they must be considered in any design, current safety regulations do not present an insurmountable roadblock to the development and manufacture of lightweight vehicles.

Pollution standards can be met without an excessive loss in performance. The proposed heat engine, designed to operate within a narrow band, could conceivably satisfy current requirements without added pollution equipment. Further, the flywheel/heat engine hybrid vehicle could provide a solution to the vehicle pollution emission problem, because of its ability to operate on flywheel power only for extended time periods. A fullycharged flywheel at $10 \mathrm{kWh}$ with regenerative braking will propel the design vehicle between 75 and $100 \mathrm{miles}$ at $30 \mathrm{mph}$ without assistance from the heat engine. For most downtown and suburban driving, the heat engine need not be operated. Thus, the hybrid vehicle local pollution emissions would be zero. Pollutants would be emitted, however, whenever the flywheel is charged by the heat engine or by any electrical means.

\section{MAINTENANCE AND OPERATION}

Maintenance required for a flywheel/heat engine hybrid will be determined primarily by the maintenance needs of the heat engine. Hybrid vehicle maintenance should not be any more difficult and time-consuming than maintenance of today's automobiles. The flywheel unit may require special attention in addition to periodic unit replacement (preventive maintenance). 
Difficulties may be encountered if the flywheel is allowed to run down completely; if the vehicle encounters a long and steep grade at a very low charge level; if the flywheel container develops a leak; if the rotor develops unexpected failure; or if the vehicle encounters an accident. However, except for accidents in which a vehicle is severely jolted and/or undergoes angular displacement, none of the difficulties appears to be catastrophic.

For general operation, the operator controls on the hybrid vehicle would be analogous to those on present vehicles. A switch would engage the flywheel clutch; a selector level transmission would permit choice of drive, neutral, or reverse; and acceleration and brake pedals would command vehicle accelerations and decelerations. The on-off operation of the engine would be controlled automatically to keep the flywheel speed within a desired range. The automatic mechanism would have a manual override to permit operation in the flywheel-only mode during urban driving. It might be practical to provide a gain control to adjust vehicle response to operator preferences and driving conditions and to give the driver the "feel" of vehicle acceleration and deceleration.

The flywheel must be recharged periodically to maintain required energy levels. The primary means of recharging is the 10-hp heat engine, which can bring the $10 \mathrm{kWh}$ flywheel from one-quarter to full charge in about 1 hour. A safety device would shut off the heat engine to avoid overcharging. If vehicle use were limited primarily to urban commuting, the heat engine could be augmented by an electric motor, which can be used to charge the flywheel. Since the flywheel drive alone has a 75 to 100-mile range, a small motor recharging the flywheel overnight may be adequate for a large range of duty cycles. 


\section{CONCLUSIONS}

The flywheel/heat engine hybrid propulsion system appears to be a very promising concept for an energy-economic vehicle drive. Potential exists for vehicles powered by spark ignition engines, which have excellent acceleration and grade-climbing characteristics, long ranges, and offer 80 to 100 miles per gallon of gasoline. Even higher fuel economies are possible with Diesel and Stirling engines. The combination offers excellent performance characteristics as an urban vehicle with a range of 75 to 100 miles on flywheel energy alone.

The biggest shortcomings of a 10-kWh flywheel are the magnitude of gyroscopic precession forces and danger from flywheel disintegration. The first can be eliminated by designing counterrotating flywheels or by decreasing the flywheel size. The second may be solved with programmed disintegration and special flywheel designs.

Another obstacle to use of the flywheel/heat engine system is the cost. The added complexity of the system, coupled with the exotic material used in the flywheel and its accessories, sum up to a relatively expensive vehicle. A detailed cost analysis will be required before a hybrid system is put into production. 


\section{REFERENCES}

1. L. J. Lawson, "Kinetic Energy Storage for Mass Transportation." Mechanical Engineering. 96(9):36-42, 1974.

2. L. J. Lawson, "Design and Testing of High Energy Density Flywheels for Application to Flywheel/Heat Engine Hybrid Vehicle Drives." Proceedings of the 6th Intersociety Energy Conversion Engineering Conference, New York, NY, 1971.

3. R. R. Gilbert, et al., Flywheel Feasibility Study and Demonstration. PB 200-143, National Technical Information Service, Springfield, VA, 1971.

4. R. R. Gilbert, et al., Flywheel Drive Systems Study Final Report. PB 213-342, National Technical Information Service, Springfield, VA, 1972.

5. R. T. Dann, "The Revolution in Flywheels." Machine Design. 45(14): $130-136,1973$.

6. D. G. Harvey and W. R. Menchen, The Automobile: Energy and Environment. Hittman Associates, Inc., Columbia, MD, March 1974.

7. D. W. Rabenhorst, "Potential Applications for the Superflywheel." Proceedings of the 6th Intersociety Energy Conversion Engineering Conference, New York, NY, 1971.

8. D. W. Rabenhorst, Material Requirements for the Superflywheel. Johns Hopkins University, Silver Spring, MD.

9. J. K. Tien, et al., "Reducing the Energy Investment in Automobiles." Technology Review. $\underline{77}(4): 38-43,1975$.

10. J. T. Kummer, "The Automobile as an Energy Converter." Technology Review. 77(4):26-37, 1975.

11. A. A. Frank, "Fuel and Emission Characteristics of a Flywheel-Heat Engine Vehicle." University of Wiscons in paper presented to the 1975 Flywheel Technology Symposium, Berkeley, CA, November 1975. 
APPENDIX A

ENGINEERING ANALYSIS

OF THE

FLYWHEEL/ICE HYBRID 


\section{ENGINEERING ANALYSIS OF THE FLYWHEEL/ICE HYBRID}

This appendix documents the methods used to predict performance of a flywheel/internal combustion engine (ICE) hybrid power plant. Although familiar terms of power plant horsepower and torque ratings are used, they must be viewed in a different frame of reference when the hybrid power plant is examined. Conventional principles of engineering mechanics form the basis of analysis.

\section{FLYWHEEL/ICE HYBRID OPERATION}

During operation of a vehicle powered by a flywheel/ICE drive system, the road demands are met entirely by the flywheel, except when the flywheel is nearly discharged. Power to the wheels is obtained by reducing flywheel speed via a continuously variable mechanical transmission. The same transmission is used for regenerative braking by converting the kinetic energy of the vehicle into kinetic energy of the flywheel. During normal operation, the internal combustion engine provides $7.5 \mathrm{~kW}$ to the flywheel until the flywheel reaches its maximum speed of 24,000 rpm. At that condition, the engine switches off automatically and the flywheel operates as the sole source of vehicle power. The engine may be switched on by the flywheel whenever the flywheel drops below a given speed, or by the operator as desired.

The TEK ${ }^{\circledR}$ transmission, available commercially, has a continuous rating of $7.5 \mathrm{~kW}$ and will safely handle momentary loads up to $50 \mathrm{~kW}$. With efficiencies of 85 to 95 percent, it appears adequate for the design vehicle. However, new designs are possible for lighter and more efficient transmissions.

A large number of flywheel materials is possible for use in future flywheel systems, as shown later in the appendix. However, the current design will utilize a steel disk of constant stress design, turning at a maximum speed of $24,000 \mathrm{rpm}$. The flywheel is charged by an internal combustion engine through a second continuously variable transmission. The transmission is of the same design as the primary transmission used to drive the vehicle except that it does not need a reverse gear. The flywheel system 
will be designed for a maximum power level of $50 \mathrm{~kW}$. For a 10-kWh flywhee1, this power level can be maintained for 12 min before being reduced to $7.5 \mathrm{~kW}$, the level of the internal combustion engine output.

\section{VEHICLE WEIGHT ESTIMATES}

The hybrid vehicle is designed for minimal weight and maximum performance. Weights of various components are shown in Table A-1.

Weight estimates are based on lightweight materials, single lightduty axle, 7.5-kW engine, and 10-kWh flywheel and transmissions described previously. These weights are dominated by the flywheel and could be reduced with high-tensile strength, low-density fiberglass materials.

TABLE A-1. Flywheel/ICE Hybrid Vehicle Weight Estimates

Component

Structure and suspension systems

Flywheel/ICE system

Flywhee 1

Housing and supports

Transmissions

ICE

Differential

Miscellaneous accessories

Miscellaneous

5-gallon fuel tank (full)

Nonitemized components

Driver and passenger
Individua 1

Weight, 1b

Combined

Weight, 1b

1,035

700

200

40

25

20

50

465

45

100

320

TOTAL WEIGHT $\overline{2,450}$ 


\section{ACCESSORY POWER}

Accessories for the hybrid vehicle were selected to be the minimum necessary for safe operation. They are listed in Table A-2, along with the anticipated power requirements.

Because the continuous demand on the flywheel is increased when the accessories are used, the vehicle range is reduced. To maintain the vehicle range, the cruising velocity must be reduced to about $45 \mathrm{mph}$ while accessories are used.

TABLE A-2. Hybrid Vehicle Accessories Power Requirements

Accessory

Service lights - front

Service lights - rear

License plates

Windshield wiper

Radio

Clock

Dash lights

Miscellaneous

Heater for motor

Accessory Load

Alternate losses ( $85 \%$ efficiency) TOTAL

Heater

Accessory power required
Required Power, Watts

48
24
10
12
60
1
18
4
20
$\frac{197}{35}$
$\frac{232}{19}=0.32 \mathrm{hp}$
$500=0.67 \mathrm{hp}$
732 watts $\cong \mathrm{hp}$

\section{FLYWHEEL ANALYSIS}

The following analysis is based on AISI 4340 steel. Critical parameters of this metal are: 
- density, $\rho=0.289 \mathrm{lb} / \mathrm{in}^{3}$

- tensile strength, $\sigma=240,000 \mathrm{lb} / \mathrm{in}^{2}$

The maximum working stress will be set to allow a factor of safety of 1-1/2 based upon the maximum distortion-energy theory of failure:

$$
\sigma_{0}=\frac{\sigma}{1-1 / 2}=160,000 \mathrm{lb} / \mathrm{in}^{2} .
$$

Maximum flywheel speed will be determined from the limiting value of $\sigma_{0}$. However, a nominal value of $24,000 \mathrm{rpm}$ will be sought:

$$
\begin{aligned}
& N_{\max }=24,000 \mathrm{rpm} \\
& \omega_{\max }=2,512 \mathrm{rad} / \mathrm{sec} .
\end{aligned}
$$

The effective minimum value of the flywheel speed will be the nost effective condition for the internal combustion engine:

$$
\begin{aligned}
& \mathrm{N}_{\text {min }}=2,400 \mathrm{rpm} \\
& \omega_{\text {min }}=251 \mathrm{rad} / \mathrm{sec} .
\end{aligned}
$$

The profile of the flywheel will be that of a constant stress disk (biaxial stress field) where

$$
\sigma_{r}=\sigma_{\theta}=\sigma_{0} \text {. }
$$

According to Den Hartog, (1) this gives

$$
t=t_{0} \exp \left(-\frac{\rho_{\omega}^{2} r^{2}}{2 g \sigma_{0}}\right)
$$

where

$$
\begin{aligned}
& \sigma_{r}=\text { radial stress, lb/in. }{ }^{2} \\
& \sigma_{\theta}=\text { tangential stress, } 1 \mathrm{~b} / \mathrm{in}^{2}{ }^{2} \\
& \sigma_{0}=\text { equivalent stress, } \mathrm{lb} / \mathrm{in}^{2}{ }^{2}
\end{aligned}
$$




\section{ACCESSORY POWER}

Accessories for the hybrid vehicle were selected to be the minimum necessary for safe operation. They are 1 isted in Table A-2, along with the anticipated power requirements.

Because the continuous demand on the flywheel is increased when the accessories are used, the vehicle range is reduced. To maintain the vehicle range, the cruising velocity must be reduced to about $45 \mathrm{mph}$ while accessories are used.

TABLE A-2. Hybrid Vehicle Accessories Power Requirements

Accessory

Service lights - front

Service lights - rear

License plates

Windshield wiper

Radio

Clock

Dash lights

Miscel1 aneous

Heater for motor

Accessory Load

Alternate losses ( $85 \%$ efficiency) TOTAL

Heater

Accessory power required
Required Power, Watts

$\begin{aligned} & 48 \\ & 24 \\ & 10 \\ & 12 \\ & 60 \\ & 1 \\ & 18 \\ & 4 \\ & \frac{20}{197} \\ & \frac{35}{232}=0.32 \mathrm{hp} \\ & 500=0.67 \mathrm{hp} \\ & 732 \text { watts } 1 \mathrm{hp}\end{aligned}$

\section{FLYWHEEL ANALYSIS}

The following analysis is based on AISI 4340 steel. Critical parameters of this metal are: 
- density, $\rho=0.289 \mathrm{lb} /$ in. $^{3}$

- tensile strength, $\sigma=240,000 \mathrm{lb} / \mathrm{in}^{2}$

The maximum working stress will be set to allow a factor of safety of 1-1/2 based upon the maximum distortion-energy theory of failure:

$$
\sigma_{0}=\frac{\sigma}{1-1 / 2}=160,000 \mathrm{lb} / \mathrm{in} .^{2} \text {. }
$$

Maximum flywheel speed will be determined from the limiting value of $\sigma_{0}$. However, a nominal value of $24,000 \mathrm{rpm}$ will be sought:

$$
\begin{aligned}
& \mathrm{N}_{\text {max }}=24,000 \mathrm{rpm} \\
& \omega_{\max }=2,512 \mathrm{rad} / \mathrm{sec} .
\end{aligned}
$$

The effective minimum value of the flywheel speed will be the most effective condition for the internal combustion engine:

$$
\begin{aligned}
& N_{\text {min }}=2,400 \mathrm{rpm} \\
& \omega_{\text {min }}=251 \mathrm{rad} / \mathrm{sec} .
\end{aligned}
$$

The profile of the flywheel will be that of a constant stress disk (biaxial stress field) where

$$
\sigma_{r}=\sigma_{\theta}=\sigma_{0} .
$$

According to Den Hartog, (1) this gives

$$
t=t_{0} \exp \left(-\frac{\rho_{\omega}{ }^{2} r^{2}}{2 g \sigma_{0}}\right)
$$

where

$$
\begin{aligned}
& \sigma_{r}=\text { radial stress, } 1 \mathrm{~b} / \mathrm{in}^{2} \\
& \sigma_{\theta}=\text { tangential stress, } 1 \mathrm{~b} / \mathrm{in}^{2}{ }^{2} \\
& \sigma_{0}=\text { equivalent stress, } 1 \mathrm{~b} / \text { in }^{2}
\end{aligned}
$$




$$
\begin{aligned}
& t=\text { disk thickness at } r, \text { in. } \\
& t_{0}=\text { disk thickness at } r=0, \text { in. } \\
& r=\text { radius, in. } \\
& e=2.71828 . . . \\
& g=386 \mathrm{in} . / \mathrm{sec}^{2}
\end{aligned}
$$

Since the critical condition is at the maximum speed, the disk profile is established at that condition as follows:

$$
\begin{aligned}
& t=t_{0} \exp \left(-\frac{(0.289)(2.512)^{2} r^{2}}{2(386)(160,000)}\right) \\
& t=t_{0} \exp \left(-0.014764 r^{2}\right)
\end{aligned}
$$

Energy stored in the flywheel is

$$
\mathrm{KE}=\frac{1}{2} \mathrm{I} \omega^{2}=10 \mathrm{kWh}=13.41 \mathrm{hp}-\mathrm{hr}=3.185 \times 10^{8} \mathrm{in.}-1 \mathrm{~b}
$$

where

$$
I=\text { moment of inertia, in. }-1 b-\sec ^{2} \text {. }
$$

The moment of inertia required to store $10 \mathrm{kWh}$ between 24,000 and 2,400 rpm is

$$
\begin{aligned}
\Delta K E & =3.185 \times 10^{8} \text { in. }-1 \mathrm{~b} \\
I_{0} & =\frac{2(\Delta K E)}{\omega_{1}^{2}-\omega_{2}^{2}}=\frac{2\left(3.185 \times 10^{8}\right)}{(2512)^{2}-(251)^{2}}=100 \text { in. }-1 b-\sec ^{2} .
\end{aligned}
$$

Knowing the inertia, thickness of the disk base may be determined.

The inertia of a constant stress disk may be found by integrating the element shown in the following sketch. 


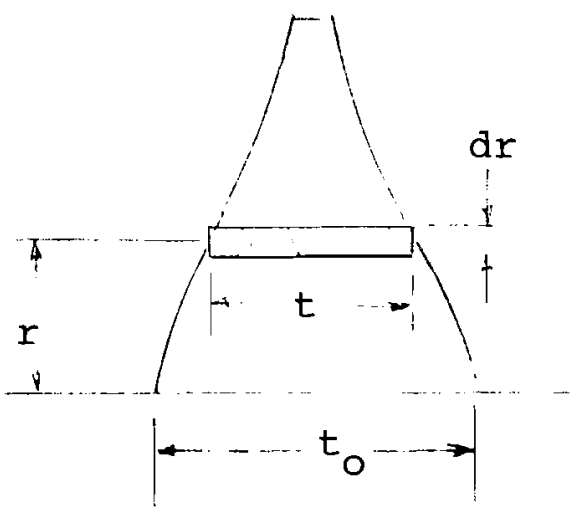

For a cylindrical element,

$$
\begin{aligned}
d_{0} & =\frac{2 \pi \rho}{g} t r^{3} d r \\
& =\frac{2 \pi(0.289)}{386} t r^{3} d r \\
& =0.00472 t r^{3} d r \\
& =0.00472 t_{0} \exp \left(-0.014764 r^{2}\right) r^{3} d r \\
I_{0} & =\int_{0}^{r} 0.00472 t_{0} \exp \left(-0.014764 r^{2}\right) r^{3} d r .
\end{aligned}
$$

Let $u=r^{2}$

$$
d v=\exp \left(-0.014764 r^{2}\right) r d r .
$$

Then $d u=2 r d r$

$$
\begin{aligned}
v & =\int_{0}^{r} \exp \left(-0.014764 r^{2}\right)(r d r) \\
& =-33.87 \exp \left(-0.014764 r^{2}\right) .
\end{aligned}
$$

Now $\int u d v=u v-\int v d u$.

$$
\begin{aligned}
I_{0}= & 0.00472 t_{0}\left[-33.87 r^{2} \exp \left(-0.014764 r^{2}\right)\right. \\
& \left.+\int_{0}^{r}-33.87 \exp \left(-0.014764 r^{2}\right) 2 r d r\right]
\end{aligned}
$$


Finally,

$$
I_{0}=0.00472 t_{0}\left[-33.87 r^{2} \exp \left(-0.014764 r^{2}\right)-2294 \exp \left(-0.014764 r^{2}\right)+c\right] \text {, }
$$

when $r=0, I_{0}=0$

$$
0=0.00472 t_{0}[0-2294+c] \text {. }
$$

Thus, $C=2294$, and

$$
\begin{aligned}
I_{0}= & 0.00472 t_{0}\left\{2294-2294 \exp \left(-0.014764 r^{2}\right)\right. \\
& \left.-33.87 r^{2} \exp \left(-0.014764 r^{2}\right)\right\} .
\end{aligned}
$$

From the last equation it is obvious that, for a given choice of $r_{\max }$, a value of $t_{0}$ and the weight of the flywheel are obtained. Two cases are discussed, $r_{\max }=12 \mathrm{in}$. and $r_{\max }=15 \mathrm{in}$.

Case A: $r_{\max }=12$ in.

$$
\begin{aligned}
& \exp \left(-0.014764(12)^{2}\right)=\exp (-2.126)=0.1193 \\
& t_{0}=\frac{100}{(0.00472)(2294-273-582)}=14.87 \mathrm{in} .
\end{aligned}
$$

Disk profile is given by

$$
\begin{aligned}
& r=0 \mathrm{in.}, t=14.87 \mathrm{in.} \\
& r=3 \mathrm{in.}, t=12.92 \mathrm{in.} \\
& r=6 \mathrm{in.}, t=9.08 \mathrm{in.} \\
& r=9 \mathrm{in.}, t=4.51 \mathrm{in.} \\
& r=12 \mathrm{in.}, t=1.77 \mathrm{in.}
\end{aligned}
$$


With a thickness of 1.77 in. at the tip, this disk does not yield a good shape factor. Furthermore, the weight of this disk is large. The disk weight may be found by integration, using a cylindrical element similar to that used before to evaluate the moment of inertia.

$$
\begin{aligned}
d V & =2 \pi r(t d r) \\
& =2 \pi r t_{0} \exp \left(-0.014764 r^{2}\right) d r \\
V & =2 \pi(14.87) \int_{0}^{12} \exp \left(-0.014764 r^{2}\right) d r \\
& =93.385\left[-33.87 \exp \left(-0.014764 r^{2}\right)\right]_{0}^{12} \\
& =3163(1-0.1193)=2786 \mathrm{in.}^{3} \\
W & =\rho V=0.289 \times 2786 \\
& =8101 \mathrm{~b} .
\end{aligned}
$$

Case B: $r_{\max }=15 \mathrm{in.}$

$$
\begin{aligned}
& \exp \left(-0.014764(15)^{2}\right)=\exp (3.322)=0.0361 \\
& I_{0}=100=0.00472 t_{0}\{2294-33.87(225)(0.0361)-2294(0.0361)\} \\
& t_{0}=\frac{100}{0.00472(2294-275-83)}=11.05 \mathrm{in} .
\end{aligned}
$$

Thus, $r=0$ in., $t=11.05$ in.

$$
r=3 \text { in., } t=9.08 \text { in. }
$$$$
r=6 \text { in., } t=6.49 \mathrm{in} \text {. }
$$$$
r=9 \text { in., } t=3.34 \text { in. }
$$$$
r=12 \text { in., } t=1.32 \text { in. }
$$$$
r=15 \mathrm{in.,} t=0.40 \mathrm{in} \text {. }
$$ 
The thickness of this disk at the tip is nearly zero, assuring a shape factor near 0.90. Furthermore, the weight of the disk is also reduced.

$$
\begin{aligned}
V & =2 \pi(11.05) \int_{0}^{15} \exp \left(-0.014764 r^{2}\right) d r \\
& =2 \pi(11.05)\left[-33.87 \exp \left(-0.014764 r^{2}\right)\right]_{0}^{15} \\
& =2350(1-0.0361)=2265 \mathrm{in.}^{3} \\
W & =\rho V=(0.289)(2265) \\
& =6541 \mathrm{~b} .
\end{aligned}
$$

A larger diameter will yield a lower weight, but may also exceed the critical stress-to-density ratio. For the above design, the energy density is

$$
E=\frac{10,000}{654}=15.3 \mathrm{~W}-\mathrm{hr} / 1 \mathrm{~b} .
$$

The critical energy density is

$$
E_{C}=\frac{\sigma}{\rho}=\frac{160,000}{0.289}=554,000 \frac{i n \cdot-1 b}{1 b}=17.4 \mathrm{~W}-\mathrm{hr} / 1 \mathrm{~b} .
$$

Thus, the energy density is sufficiently low to permit the 15-in. disk to be a candidate flywheel for the hybrid vehicle. The shape factor for the constant stress design is 1.0 for a purely exponential disk. For the case examined here, the shape factor required is about 0.88 . Note that this includes a factor of safety of 1-1/2 based upon maximum tensile stress.

\section{ROAD LOAD REQUIREMENTS}

Road load requirements can be described in terms of several major factors: aerodynamic resistance, rolling resistance, acceleration, and grades. 
Aerodynamic resistance is given by Taborek ${ }^{(2)}$ as

$$
P_{A}=0.12 C_{A} A(V / 10)^{2}
$$

where $\quad P_{A}=$ aerodynamic drag force, $1 \mathrm{bs}$

$$
\begin{aligned}
& C_{A}=0.42 \text { (aerodynamic drag coefficient) } \\
& A=16 \mathrm{ft}^{2} \text { (frontal area) } \\
& V=\text { velocity, ft/sec. }
\end{aligned}
$$

For the subject vehicle,

$$
P_{A}=0.00768 V^{2} \text {. }
$$

Rolling resistance ${ }^{(2)}$ can be estimated by

$$
P_{R}=0.008 W+2.021 \times 10^{-7} W V^{2}
$$

where $W=$ vehicle weight, 1 bs.

Combining aerodynamic and rolling resistances,

$$
P=0.008 W+\left(0.00768-2.021 \times 10^{-7} W\right) V^{2}
$$

For a 2000-1b vehicle,

$$
P=16+\left(8.08 \times 10^{-3}\right) v^{2}
$$

In terms of power required at the wheels,

$$
\begin{aligned}
& H P=P V / 550 \mathrm{hp} \\
& H P=0.0291 \mathrm{~V}+0.0147 \times 10^{-3} \mathrm{~V}^{3} \mathrm{hp} . \\
& \text { Tractile effort can be estimated as }
\end{aligned}
$$

$$
\mathrm{P}_{\mathrm{T}}=\mathrm{W}_{\phi / 100}
$$

where $\phi=$ grade, in percent. 
In terms of power

$$
H P_{T}=W \phi V / 55,000=0.03636 \phi V
$$

for a vehicle weighing $20001 \mathrm{bs}$.

Power required to accelerate a vehicle at constant rate "a" is

$$
H P_{a}=W a V / 550=3.636 \mathrm{aV}
$$

where "a" is acceleration level in gs. (a)

To summarize, the total power required at wheels to overcome road load requirements and to accelerate at a constant rate "a" up a grade $\phi$ is

$$
H P=0.0291 V+0.0000147 V^{3}+0.03636 \phi V+3.636 a V
$$

Case A

Power requirements for constant speed are as follows:

\begin{tabular}{cc}
$\begin{array}{c}\text { Velocity, } \\
\mathrm{ft} / \mathrm{sec}\end{array}$ & $\begin{array}{c}\mathrm{HP}, \\
\mathrm{hp}\end{array}$ \\
\hline 10.0 & 0.31 \\
20.0 & 0.70 \\
30.0 & 1.27 \\
40.0 & 2.11 \\
50.0 & 3.30 \\
60.0 & 4.92 \\
70.0 & 7.07 \\
73.3 & 7.92
\end{tabular}

Assuming transmission and axle efficiency of 0.9 , the maximum power required at $50 \mathrm{mph}(73.3 \mathrm{ft} / \mathrm{sec})$ is $8.80 \mathrm{hp}$.

Case B

Power required at wheels to accelerate the vehicle at a constant rate of $0.3 \mathrm{~g}$ to $70 \mathrm{ft} / \mathrm{sec}(47.7 \mathrm{mph})$ on level ground is determined by:

(a) The abbreviation $\mathrm{g}$ is used here to indicate gravitational force. 


$$
\begin{aligned}
H P & =0.0291 V+0.0147 \times 10^{-3} V^{3}+3.636(0.3) V \\
& =1.12 V+1.47 \times 10^{-5} V^{3}
\end{aligned}
$$

\begin{tabular}{|c|c|c|c|c|c|c|}
\hline $\begin{array}{l}\Delta t \\
\text { sec }\end{array}$ & $\begin{array}{l}\Sigma \Delta t \\
\text { sec } \\
\end{array}$ & $\begin{array}{c}V \\
\mathrm{ft} / \mathrm{sec} \\
\end{array}$ & $\begin{array}{l}\text { HP } \\
\text { hp }\end{array}$ & $\begin{array}{c}\text { Mean HP } \\
\mathrm{hp} \\
\end{array}$ & $\begin{array}{c}\triangle K E \\
\text { hp-sec }\end{array}$ & $\begin{array}{c}\Sigma \Delta K E \\
\text { hp-sec }\end{array}$ \\
\hline 1.035 & 1.035 & 10 & 11.21 & 5.61 & 5.81 & 5.81 \\
\hline 1.035 & 2.070 & 20 & 22.52 & 16.87 & 17.46 & 23.27 \\
\hline 1.035 & 3.105 & 30 & 34.00 & 28.26 & 29.25 & 52.52 \\
\hline 1.035 & 4.140 & 40 & 45.74 & 39.87 & 41.27 & 93.79 \\
\hline 1.035 & 5.175 & 50 & 57.84 & 51.79 & 53.60 & 147.39 \\
\hline 1.035 & 6.210 & 60 & 70.37 & 64.11 & 66.35 & 213.74 \\
\hline 1.035 & 7.245 & 70 & 83.44 & 76.91 & 79.60 & 293.34 \\
\hline
\end{tabular}

At $0.3 \mathrm{~g}, V=9.66 \mathrm{t}$ and $\Delta t=1.035 \mathrm{sec}$ for each $10 \mathrm{ft} / \mathrm{sec}$.

Thus, $293 \mathrm{hp}-\mathrm{sec}(0.081 \mathrm{hp}-\mathrm{hr})$ are required to accelerate the vehicle from 0 to $70 \mathrm{ft} / \mathrm{sec}$. The maximum horsepower required (80) is well within flywheel system capabilities. Note that conversion efficiencies of transmission and differential are neglected here. In the above table,

$$
\Delta K E=H P \times \Delta t
$$

\section{Case C}

Power required at wheels to accelerate the vehicle to $60 \mathrm{ft} / \mathrm{sec}$

(41 $\mathrm{mph}$ ) at a constant rate of $0.1 \mathrm{~g}$ on a 20 percent grade is:

$$
\begin{aligned}
H P & =0.0291 V+0.0147 \times 10^{-3} V^{3}+0.03636(20) V+3.636(0.1) V \\
& =1.120 V+1.47 \times 10^{-5} V^{3}
\end{aligned}
$$

At $0.1 \mathrm{~g}, V=3.22 \mathrm{t}$ and $\Delta t=3.106 \mathrm{sec}$ for each $10 \mathrm{ft} / \mathrm{sec}$ increment. The horsepower and energy requirements are: 


\begin{tabular}{|c|c|c|c|c|c|c|}
\hline $\begin{array}{l}\Delta \mathrm{t} \\
\mathrm{sec}\end{array}$ & $\begin{array}{l}\Sigma \Delta t \\
\sec \end{array}$ & $\begin{array}{c}V \\
\mathrm{ft} / \mathrm{sec} \\
\end{array}$ & $\begin{array}{l}\text { HP } \\
\mathrm{hp}\end{array}$ & $\begin{array}{c}\text { Mean HP } \\
\text { hp } \\
\end{array}$ & $\begin{array}{c}\Delta K E \\
h p-s e c\end{array}$ & $\begin{array}{r}\Sigma \Delta K E \\
h p-s e c\end{array}$ \\
\hline 3.106 & 3.106 & 10 & 11.21 & 5.61 & 17.43 & 17.43 \\
\hline 3.106 & 8.212 & 20 & 22.52 & 16.87 & 52.40 & 69.82 \\
\hline 3.106 & 9.318 & 30 & 34.00 & 28.26 & 87.78 & 157.60 \\
\hline 3.106 & 12.424 & 40 & 45.74 & 39.87 & 123.84 & 281.44 \\
\hline 3.106 & 15.530 & 50 & 57.84 & 51.79 & 160.86 & 442.30 \\
\hline 3.106 & 18.636 & 60 & 70.37 & 64.11 & 199.13 & 641.43 \\
\hline
\end{tabular}

The total energy required to accelerate the subject vehicle from 0 to $41 \mathrm{mph}$ on a 20 percent grade is $641 \mathrm{hp}-\mathrm{sec}(0.17 \mathrm{hp}-\mathrm{hr})$ and the minimum power is $70 \mathrm{hp}$, again well within flywheel system capabilities.

\section{FUEL ECONOMY AT CONSTANT SPEED}

At constant speed on a level roadway, power at wheels is a function of velocity. From the previous section,

$$
H P=0.0291 \mathrm{~V}+0.0000174 \mathrm{~V}^{3}
$$

for a 2000-1b vehicle. Assuming $49.1 \mathrm{hp}-\mathrm{hr}$ per gallon of gasoline, a 33 percent 0t to cycle efficiency, a 0.90 percent efficiency of transmission and differential, and $1.5 \mathrm{hp}$ for other losses, the mileages for a hybrid vehicle are:

$\begin{array}{ccc}\begin{array}{c}V \\ \mathrm{ft} / \mathrm{sec}\end{array} & \begin{array}{c}\sum H P \\ \mathrm{hp}\end{array} & \begin{array}{c}\text { Consumption, } \\ \mathrm{mpg}\end{array} \\ 20 & 2.28 & 97 \\ 30 & 2.91 & 114 \\ 40 & 3.84 & 115 \\ 50 & 5.17 & 107 \\ 60 & 6.97 & 95 \\ 70 & 9.36 & 83 \\ 73.3 & 10.30 & 79\end{array}$


Thus, the maximum fuel economy is $115 \mathrm{mpg}$ at $40 \mathrm{ft} / \mathrm{sec}(27 \mathrm{mph})$ and decreases to about $80 \mathrm{mpg}$ at $73.3 \mathrm{ft} / \mathrm{sec}(50 \mathrm{mph})$. For a vehicle weighing $2500 \mathrm{lbs}$, these mileages would decrease by about 25 percent over the entire range of speeds.

\section{URBAN AREA FUEL ECONOMY}

If the proposed vehicle is equipped with a regenerative braking system, the net effect of a large number of accelerations, decelerations, and long idling periods on vehicle gas consumption will be minimal. Idling time will have no effect at a11, since, unlike a conventional vehicle, idling time is used to charge the flywheel and no energy is wasted. Acceleration at $0.30 \mathrm{gs}$ to $40 \mathrm{ft} / \mathrm{sec}$ uses $0.03 \mathrm{hp}$ - hr of energy, or, approximately 30 stops are required within an hour to deplete $1 / 10$ of the total flywheel energy stored. With regenerative braking, about 60 percent of the energy lost to braking friction can be recovered; only $0.01 \mathrm{hp}-\mathrm{hr}$ of energy is lost in each acceleration. At $40 \mathrm{ft} / \mathrm{sec}$, the total energy used is then $3.84+30 \times 0.01=$ $4.14 \mathrm{hp}-\mathrm{hr}$, and expected urban mileage is $106 \mathrm{mpg}$ compared to $115 \mathrm{mpg}$ at best conditions.

\section{FLYWHEEL WINDAGE LOSSES}

An important factor in flywheel system design is the windage loss associated with the high speed of a rotating flywheel. This loss must be kept under $0.5 \mathrm{hp}$ if the flywheel system is to be effective. An empirical relationship used by Lockheed ${ }^{(3)}$ gives approximate windage power losses as

$$
H P=0.006\left(1+\frac{2.3 t}{R}\right)\left(\frac{P}{T}\right)^{0.8}\left(\frac{N}{104}\right)^{2.8}(R)^{4.6}(\mu)^{0.2}
$$

where

$$
\begin{aligned}
H P & =\text { steady-state windage loss, horsepower } \\
t & =\text { tip thickness, inches } \\
R & =\text { radius of } f 7 y \text { whee } 1, \text { inches } \\
P & =\text { air pressure, } p s i a \\
T & =\text { temperature, }{ }^{\circ} \mathrm{R} \\
\mathrm{N} & =\text { rotational speed, } \mathrm{rpm} \\
\mu & =\text { air viscosity, } \mathrm{Ib} / \mathrm{hr}-\mathrm{ft}
\end{aligned}
$$


The steady-state windage loss calculation is for an unshrouded disk rotating in an incompressible gas in the subsonic region. The losses may be reduced substantially with an optimized shroud.

Table A-3 shows windage loss as a function of pressure. Tabular values are based on the following parameters:

$$
\begin{aligned}
& N=24,000 \mathrm{rpm} \\
& R=15 \text { inches } \\
& t=0.40 \text { inches } \\
& T=520^{\circ} \mathrm{R} \\
& \mu=0.043 \mathrm{lb} / \mathrm{hr}=\mathrm{ft} .
\end{aligned}
$$

The table indicates that vacuum levels of 0.0001 atmospheres or better are desirable to hold the pumping loss to $0.5 \mathrm{hp}$ or less.

TABLE A-3. Pressure-Windage Loss Relationships

\begin{tabular}{lc}
\multicolumn{1}{c}{$\begin{array}{c}\text { Pressure, } \\
\text { psi }\end{array}$} & $\begin{array}{c}\text { Steady-State } \\
\text { Windage Loss, } \\
\text { hp }\end{array}$ \\
$0.01 \mathrm{~atm}=0.147$ & 14.6 \\
$0.001 \mathrm{~atm}=2.0147$ & 2.3 \\
$0.0001 \mathrm{~atm}=0.00147$ & 0.37
\end{tabular}

The vacuum system seals used determine the maximum maintainable flywheel vacuum. Dynamic sealing with magnetic fluids (ferrofluidic seals) can provide nearly zero leakage at high speeds. Recently, vacuum seals have been built for speeds to $120,000 \mathrm{rpm}$ and for vacuums to $10^{-3}$ torr $\left(10^{-6} \mathrm{~atm}\right)$. Thus, holding high vacuums appears to be possible. Magnetic-liquid seals provide a positive hermetic barrier in vacuum systems with leaks of less than $10^{-11}$ standard $\mathrm{c} / \mathrm{sec}$ of helium. 


\section{REFERENCES}

1. J. P. Den Hartog, Advanced Strength of Materials. McGraw-Hill Publishers, New York, NY, 1952.

2. J. J. Taborek, Mechanics of Vehicles. Penton Publishing Co., Cleveland, $\mathrm{OH}, 1957$.

3. R. R. Gilbert, et al., Flywheel Feasibility Study and Demonstration. $P B$ 200-143, National Technical Information Service, Springfield, VA, 1971. 


\section{DISTRIBUTION}

No. of

Copies

OFFSITE

1 A. A. Churm

ERDA Chicago Patent Group

Chicago Operations office

9800 South Cass Avenue

Argonne, IL 60439

27 ERDA Technical Information Center

1 G. C. Chang

Energy Research and Development Administration

Division of Energy Storage Conservation

Washington, DC 20545

1 K. Barber

Energy Research and

Development Administration

Division of Transportation

Washington, DC 20545
No. of

Copies

27

Battelle-Northwest

B. M. Johnson

W. S. Kelly

W. V. Los cutoff (10)

D. E. Olesen

M. G. Patrick

L. T. Pedersen

D. E. Rasmussen

D. L. Reid

G. C. Smith

A. M. Sutey

D. S. Trent

M. Vagins

R. L. Watts

N. G. Wittenbrock

Technical Information (3)

Technical Publications

ONSITE

2 ERDA Richland Operations Office

Research and Development

Programs Division

B. J. Melton

Environmental, Safety and

Technical Services Division

P. J. Holsted 